\title{
ENTRE O FÓRUM E A EMPRESA: A INTERSECÇÃO ENTRE A FORMAÇÃO JURÍDICA E A LIDERANÇA EMPRESARIAL EM SÃO LUÍS DO MARANHÃO NO ENTRESSÉCULOS XIX-XX
}

Diogo Guagliardo Neves; Pilar Bacellar Palhano Neves*

Resumo: O "bacharelismo" é assimilado como um conjunto tipológico definidor da elite “intelectual" brasileira e sua inserção e visão de mundo em determinado período histórico. Porém, as Ciências Sociais podem contribuir para uma percepção mais alargada das regras postas nas sociedades periféricas, especialmente para a obtenção de cargos de liderança. Conjugado a múltiplos fatores como as interligações familiares e de compadrio, o Direito é um elemento de diferenciação, mas não o único, para quem está em concorrência, inclusive em instituições como a Associação Comercial do Maranhão no Entresséculos. Em uma configuração onde não há especialização profissional, a figura do "bacharel” desaparece.

Palavras-chave: Direito. Empresários. Elites. Entresséculos. Maranhão

BETWEEN THE COURT AND THE COMPANY: THE INTERSECTION BETWEEN LEGAL FORMATION AND BUSINESS LEADERSHIP IN SÃO LUÍS DO MARANHÃO BETWEEN THE NINETEENTH AND TWENTIETH CENTURIES

Abstract: "Bacharelism" is considered as a defining typological set of the Brazilian "intellectual" elite and its insertion and vision of the world in a certain historical period. However, social sciences can contribute to a broader perception of the rules of peripheral societies, especially for leadership positions. Combined with multiple factors such as family and friendship links, Law is an element of differentiation, but not the only one, for those who are in competition, even for institutions such as the Maranhão Comercial Association between centuries. Where there is no professional specialization, the figure of the "bachelor" disappears.

\footnotetext{
"Diogo Guagliardo Neves. É bacharel em Direito pela Universidade Ceuma (2005) e bacharel em História pela Universidade Federal do Maranhão - UFMA (2005). Mestre em Ciências Sociais pela Universidade Federal do Maranhão - UFMA (2010). É doutor em Ciências Sociais pela Universidade Federal do Maranhão - UFMA (2016). É advogado. É professor do curso de Direito da Universidade Ceuma. Contato: diogogualhardoneves@hotmail.com.

Pilar Bacellar Palhano Neves. Advogada, Mestre em Gestão de Programas e Serviços de Saúde (Universidade Ceuma), Graduada em Direito (UFMA), Especialista em Direito do Trabalho (Universidade Ceuma), MBA Executivo em Saúde (FGV), Diretora Executiva e Assessora Jurídica do Instituto Ruy Palhano. Já atuou como Assessora Jurídica do Ministério Público Federal (Procuradoria da República no Maranhão). Contato: pilarbacellar@hotmail.com.
} 
Keywords: Law. Businessmen. Elite. Maranhão. Between centuries

\section{Introdução}

A ideia de que o monopolista do conhecimento jurídico, ou o "bacharel”, é a referência central para a interpretação das relações de poder no Brasil surge nos meios intelectuais no início dos anos 1920, encontrando ampla guarida na Semana de Arte Moderna e seus desdobramentos, como designativo de uma história coletiva de pseudo ou abstrata erudição, a ser abandonada e substituída por uma nova postura, inspirada no que seria "autêntico" para a experiência nacional (ANDRADE, 1928).

Na década seguinte, o portador do diploma jurídico é recepcionado no surgimento da Sociologia e da História como disciplinas acadêmicas no país, enquanto tipo ideal característico e responsável pela estratificação social, cujo auge de domínio teria se dado na passagem do Império à República, antes de enfrentar a concorrência de outros agentes, como "engenheiros" e "economistas". Nesse sentido, busca-se no passado colonial e no medievo português sua origem, tentando-se estruturar a dualidade que teria marcado os dois países, ora entre o mundo rural versus urbano, litoral versus interior, administradores versus administrados, e, por fim, à oposição entre o ideal teórico importado da Europa versus o real e prático vivenciado nos trópicos, isso tudo aliado a um processo modernizador tanto acelerado quando incompleto (FREYRE, 2002; HOLANDA, 1995).

Ocorre que a titulação em Direito não é uma constituinte absolutista de um agente de sucesso que, a partir da posse do diploma, ou de sua entrada nas profissões jurídicas, define as relações sociais ou caracteriza o Estado. Enquanto capital de diferenciação (BOURDIEU, 2007) frente aos leigos, a passagem pela universidade é importante, mas deve ser articulada com outros recursos como laços familiares, compadrios e reciprocidades, cumprimento de ritos coletivos, dentre outros. Mais ainda, a importância do portador simbólico do Direito se dilui interna corporis, quando os demais em concorrência se tornam pares, pois também possuem o mesmo elemento em suas trajetórias.

Em outra perspectiva, o designativo de "bacharel" para expressar uma categoria de agente próprio das elites "econômicas" ou "intelectuais" (em que pese a indistinção desses domínios), e que teria atravessado um processo evolutivo no decurso do tempo desde a Colônia, perde sentido quando se vislumbra que muitos deles nunca foram ou não são todo o tempo “juristas”, ou qualquer expressão de designe uma especialização profíssional. 
Ademais, a suposta concorrência que enfrentariam de outras "categorias", na verdade, não importa na existência de fato de uma oposição, pois, a opção em fase posterior por uma ou outra profissão diferente não significa muita coisa além disso mesmo. As mudanças na tipologia dos diplomas atendem, no mais, às demandas temáticas gerais a partir da complexificação econômica, por exemplo, e não pela entrada efetiva e massiva de agentes provenientes de outras camadas sociais.

De fato, em boa medida, os economistas que assumem postos relevantes da Administração nos anos 1950 são filhos ou netos dos bacharéis imperais ou republicanos. Não apenas isso. Apesar de, numericamente, os formados em Direito comporem ampla maioria se considerados os perfis coletivos, os diplomas não vinculam o agente aos postos de liderança ("profissionais", "setoriais", político-eleitorais, etc.), posto que até mesmo indivíduos desprovidos deles, podem eventualmente ocupa-los.

Essas descobertas, no entanto, somente podem ser observadas através do estudo das trajetórias individuais, levantando-se dados que precedem mesmo o nascimento e morte dos agentes, para se conhecer do legado social recebido dos ancestrais e entregue aos descendentes. Na presente abordagem, pretende-se demonstrar essas múltiplas variáveis através de um caso radical: os "bacharéis" que são "empresários”, elegendo-se como campo de pesquisa os quadros dirigentes da Associação Comercial do Maranhão no Entresséculos.

A Associação Comercial do Maranhão era entidade de primeira grandeza nas esferas locais, desde o final do Império e até meados do século XX. A reunião dos mais prósperos comerciantes e industriais em um único organismo fazia com que as decisões mais importantes da ordem política passassem por suas salas. Isso foi oficializado através de seu reconhecimento como de utilidade pública em 1917, e, em 1942, como órgão técnico-consultivo da Administração Estadual. Dessa forma, se coloca como objeto de interesse para a observação das configurações de uma parte importante das "elites" do território no lapso temporal delimitado.

\section{Referenciais teóricos}

Os condicionantes basilares das relações entre agentes para a tomada dos cargos de poder nem sempre estão claramente demonstrados, e exigem atenção sobre as origens pessoais 
e familiares, os vínculos de identificação e aproximação com outros, as fortunas por eles constituídas ou herdadas, e as estratégias implementadas para a perpetuação do controle das posições pretendidas.

Conquanto se fale em "bacharelismo" ou "lideranças empresariais" como representações de uma seção da elite "intelectual" ou "econômica", é necessário definir o seu significado. O termo "elite", para os propósitos desse trabalho, está relacionado a um grupo de agentes numericamente menor que o conjunto da população de uma determinada conformação, cuja condição de "superioridade" não é exclusivamente dependente do controle de capitais financeiros. Antes se vinculam ao domínio de uma série de recursos que lhes asseguram a ocupação de lugares estratégicos e os tornam capazes de estipular normas de conduta e comportamento ao conjunto social no qual se inserem.

Assim, no processo de hierarquização estão envolvidos uma série de elementos que servem à distinção social. Isso não poderia deixar de ser diferente quanto ao tipo de "elite" abordada, constituída, na passagem dos dois últimos séculos, quando sequer mesmo podem os agentes receber a classificação de "juristas" ou de "empresários", tamanha a heterogeneidade profissional verificada. Maneira tal que se utiliza os contributos teóricos de Offerlé (2009), para quem esse tipo de "interprofissionalização", ou reagrupamento de patrões de setores diversos, pode demonstrar a constituição de relações de sociabilidade fundadas entre subgrupos das elites locais interessados em assumir postos de liderança em outras instâncias que estão relacionadas à atividade empresarial, como a política e o Direito.

Contudo, um problema se estabelece quando se fala das "fronteiras externas" da organização, no caso, das confederações de entidades patronais (mas que podem ser aplicadas em instituições de justiça como os tribunais, conselhos de advogados, promotores de justiça e afins), que por sua vez aludem à questão de quem está incluído no grupo de líderes e quais são os grupos que podem ser reunidos quanto ao fim comum. Sobre isso, não é menor a importância de recordar que no Maranhão oitocentista a especialização profissional é inexistente, não só pelos múltiplos capitais investidos nos mais variados domínios, como também pelas próprias origens sociais e trajetórias dos agentes.

Apesar do Tribunal de Justiça do Maranhão ter surgido no Período Joanino, em 1813, com o nome de "Relação do Maranhão", a primeira faculdade de Direito efetivamente organizada é de mais de um século depois, tendo aparecido em 1918. Por outro lado, se a primeira organização de comerciantes maranhenses data de 1854, as mais antigas são a Associação Comercial do Rio de Janeiro, de 1809, e a Associação Comercial da Bahia, de 1811. 
Em outra figura, a representação e a representatividade, advindas das posições de poder mais elevadas na instituição, terminam sendo contribuintes basilares da consagração pessoal, tornando-se essa, desde logo, a sua função precípua. No caso, pouco parece importar para a seleção das lideranças desse tipo de elite, exclusivamente, as atividades econômicas ou intelectuais controladas pelos indivíduos. A uma porque tal não seria possível, considerando as estratégias postas em jogo, inclusive a pluralidade e diversificação de investimentos nesse espaço. A duas, porque a entidade em seus objetivos práticos, como outras de natureza semelhante nas sociedades periféricas, era francamente "aberta", não rejeitando, a priori, qualquer dos candidatos ingressantes, especialmente se os novatos possuíssem vínculos enfatizando-se os familiares - com o núcleo interno já estabelecido.

Propõe-se aqui abordar as relações de poder e estruturas de capital em disputa. Contribuintes a esse esquema de análise, os trabalhos de Wolf (1980), Mills (1957) e Landé (1977), que trazem uma luz sobre as relações de reciprocidade, intermediação e dos processos de personificação, fundamentos básicos das trocas realizadas entre os grupos e os agentes participantes. Dessa forma, a "extraordinariedade" intelectual atribuída a certos "juristas" ou “empresários", e a consequente personificação dos recursos sociais em jogo, constituem os seus capitais políticos, pressupostos fundamentais da dominação carismática:

[...] a posse de recursos sociais conversíveis em capital e dominação política pode apresentar-se e ser vista, estatutariamente, como "qualidades superiores" de seu possuidor. Além disso, como a dominação carismática, apesar da existência de categorização e abstração dos produtos políticos através da formação de organizações e programas formais, o portador desses recursos tem condições de ser visto (e mesmo se perceber) como seu criador. (CORADINI, 1998, p. 230).

Dessa maneira, busca-se compreender como os recursos sociais se constituem como elementos determinantes para os processos de hierarquização e indistinção profissional/institucional. Aqui, o acesso ao título acadêmico do saber jurídico e sua conjugação a instâncias de liderança na área econômica, no caso, a Associação Comercial do Maranhão, são tributários de um perfil de quem não é nem "jurista", nem "empresário" e nem "político" apenas, mas detentor de capacidades "incomuns" aos demais indivíduos, e que são habilitantes para os agraciados. 
Deve-se considerar que a atuação política dos agentes, apesar da inserção nos legislativos (locais, regionais ou central), é apenas mais uma das múltiplas dimensões de seus investimentos, mas nem sempre foi a que demandou maior dedicação de recursos (tempo, ativação de laços sociais, capital financeiro), e por isso também não pode ser pensada "isoladamente".

A concorrência política se relaciona com a formação acadêmica e, em alguma medida, à produção escrita - e escrever nesse contexto é sempre um ato diretamente político "[...] Dada a inexistência de um campo intelectual autônomo no século XIX brasileiro" (ALONSO, 2002, p. 38) - direcionado à elaboração de projetos relacionados a elementos que são apresentados como sendo próprios da competência estatal, entre eles a "economia", "educação", "cultura", etc. Isso se verifica desde a identificação do "problema" até sua "superação", englobando inclusive as justificativas de "erros" e "acertos", dentro de um jogo altamente disputado entre quem é ou não apto a conduzir o esquema “diagnóstico/tratamento/cura/profilaxias”, bem como os modos como isso se operacionalizaria.

Nesse sentido, a formação e afirmação de uma personalidade capaz de "compreender" os "problemas" e apresentar "soluções" para eles poderia redundar em lucros sociais nos mais variados investimentos, inclusive os políticos, e não apenas nos cargos eletivos, mas em todos aqueles vinculados à administração estatal, de primeiro ou segundo escalão, como secretarias de governo, corpo técnico, etc. Quer-se dizer com isso que, no contexto de uma sociedade pouco letrada, as diferenças entre os gêneros e temas de escrita não são propriamente elementos muito importantes para a configuração do "bacharel". Isso indica, de igual forma, que inexiste (ou que haja necessidade de existir) uniformidade capaz de fixar um marcador de comprometimento de estilo ou de ideias.

Se na Europa, principalmente na França, na segunda metade do século XIX, a divisão entre "produtores políticos" e os "produtores intelectuais" era mais ou menos nítida, no Brasil, no mesmo período, a conjugação das duas atividades era a própria definição do agente apto a administrar o Estado, através do concurso eleitoral (ALONSO, 2002). Além do mais, "Até mesmo as rupturas estéticas e teóricas se coadunam com as agendas das classes dirigentes e suas estratégias em definir a 'cultura nacional', através da seleção de influencias externas sob a égide dos projetos de 'nação', cuja unidade é raramente posta em questão.” (REIS, 2013, p. 33).

Dessa forma, a produção intelectual está diretamente relaciona à experiência prática de seus produtores. As “[...] representações e comportamentos estão já articulados em 
‘estratégias de ação’, criadas pelos agentes sociais [...]. Há uma complementaridade entre textos e formas de ação. Escritos e práticas se unificam politicamente.” (ALONSO, 2002, p. 39). Ou seja, o trabalho "intelectual" se articula com o esforço político na tomada de posição e hierarquização de agentes. Nesse ambiente, as figuras reificadas do "bacharel" e do "bacharelismo" se diluem.

\section{Desenvolvimento}

A figura de proa da Associação Comercial do Maranhão, sem dúvida, é o dinamarquês Martinus Hoyer, pois, é ele o principal organizador da "Comissão da Praça", entidade antecessora. Existe uma pintura a óleo retratando-o, em tamanho natural, exposta no salão nobre da organização e mandada fazer após seu falecimento em 1881.

A priori, Hoyer nada tem a ver com o Direito. Dedicou sua vida aos empreendimentos econômicos, organizando dois bancos locais, a primeira empresa a fornecer água encanada na capital (“Companhia de Águas de São Luís”), fomentou a "Companhia Progresso Agrícola”, que ergueria a maior agroindústria da época ("Engenho Central São Pedro de Alcântara") na região e mesmo publicou cinco livros, abordando temáticas como o meio circulante e os tributos.

Martinus Hoyer chega bastante jovem ao Maranhão, por volta das décadas de 1820 e 1830, trabalhando como encarregado de ordens em um navio de comércio. Desprovido dos recursos à disposição dos agentes já articulados no jogo intelectual-político, provavelmente não seria sequer conhecido caso não tivesse ele próprio se engajado ao mesmo sistema familiar de apadrinhamento e proteção preexistentes. No entanto, seu caso é exemplar por demonstrar como o pertencimento às redes de parentesco já estabelecidas nas diversas instâncias de poder poderiam proporcionar ao jovem imigrante, mesmo de origem geográfica não-lusitana, um ingresso exitoso na carreira de empresário. E aqui surge o Direito.

Havia laços familiares via matrimônio entre Hoyer e os descendentes do apresador de índios e grande lavrador do Maranhão do século dezoito, o irlandês Lourenço Belfort (Lawrence ou Lancellote, como citam alguns documentos), e daí não deve ter tido maiores problemas em acessar as mais importantes instâncias de poder da antiga província. Isso porque eram nobres fidalgos portugueses, titulares nobiliárquicos locais e portadores do saber jurídico, entre eles: 
Sebastião Gomes da Silva Belfort, “[...] estudante de matemática por Coimbra, acadêmico de direito, sem concluir o curso, vereador à Câmara Municipal de São Luís, membro da junta governativa presidida por d. Joaquim de N. S. de Nazaré. Era fidalgo cavaleiro da Casa Real portuguesa e cavaleiro da Ordem de Cristo. Faleceu no posto de brigadeiro do regimento de milícias do Itapecuru [...]" (COUTINHO, 2005, p. 237), Antônio Raimundo Teixeira Vieira Belfort, Barão do Gurupi “[...] bacharel em direito, magistrado, parlamentar [...]" (COUTINHO, 2005, p. 282), Joaquim Raimundo Nunes Belfort, Barão de Santa Rosa "[...] lavrador, político, proprietário de engenhos de açúcar [...] varão de muitas letras, mas era político liberal de prestígio e republicano histórico [...] na exposição do açúcar e do algodão ocorrida em 1883, promovida pela Associação Comercial do Maranhão, sob a chancela do presidente da província Ovídio João Paulo de Andrade, entre os que receberam menção honrosa pela qualidade superior de seus produtos, incluía-se o barão de Santa Rosa.” (COUTINHO, 2005, p. 344-345), Manoel Gomes da Silva Belfort, Barão de Coroatá, "Foi vereador à Câmara Municipal de São Luís, deputado provincial em várias legislaturas e, por duas vezes, presidente da Assembléia." (COUTINHO, 2005, p. 444).

Outra trajetória de interesse é a de Ana Joaquina Jansen Pereira (1787-1869). Uma das mais ricas mulheres de seu tempo, proprietária de terras e vasta escravaria, no interior da Província e em São Luís, onde também detinha grande número de imóveis urbanos, dos quais retirava aluguéis. Era a principal referência na liderança do Partido Liberal do Maranhão. Segundo informa Dunshee de Abranches (1992, p. 56), contava-se na cidade que:

No seu palacete, dizia o povo, não se fechavam as portas nem se apagavam as luzes. Dia e noite, ferviam ali dentro as tricas políticas e os enredos privados da terra. Nada se fazia sem a palavra de ordem ou aquiescência do sobrado...Chamavam simplesmente assim o famoso imóvel de azulejos da Rua Grande [...].

Ana Jansen nascera sem posses, porém. Sua estratégia de ascensão social se deu pela via matrimonial. Casou-se inicialmente com Antônio Lobo da Silva Leite. Enviuvando, desposou em seguida um militar, o Coronel de Milícias, e muito rico comerciante português, Isidoro Rodrigues Pereira. Com o falecimento deste em 1825, ela passa a conduzir o vasto patrimônio legado pelo agora desaparecido esposo. Ainda casaria com Antônio Xavier da Silva Leite, com o qual não teve descendentes. De qualquer maneira, a linhagem não enfrentaria mais grandes problemas. Ana Augusta Jansen Pereira, filha havida antes do terceiro matrimônio, no dia 15 de janeiro de 1839, teve núpcias com um parente próximo, Manuel Jansen Ferreira, 
advogado, professor e posteriormente comerciante, um dos mais influentes diretores da Associação Comercial do Maranhão.

Analisando-se o conjunto de diretores dessa instituição entre 1880 e 1940, foram encontradas informações (REVISTA...1925-1954) de que 16 deles se tornaram graduados em nível superior, contra outros 11 que não haviam frequentado escolas, ao menos as oficiais. A diferença, qual seja, os com formação escolar não acadêmica, e os portadores de titulação de ensino superior, é resolvida por 2 que se matricularam em universidades, mas, por impedimentos supervenientes, não puderam concluí-las e ainda outros 2 que acumularam mais de uma titulação.

Para a primeira ocorrência, tem-se Arnaldo Júlio Corrêa, que estudou Direito em Coimbra, porém, antes de sua conclusão, teve que retornar ao Maranhão a fim de assumir a chefia do empreendimento comercial que a família mantinha em São Luís. Para a segunda, Eduardo Aboud, que matriculado no "Curso Comercial" do Centro Caixeiral, o qual frequentava pela manhã, terminou se formando como "Guarda-Livros", função que modernamente seria análoga à de Contador. No ano de 1937, já um dos maiores comerciantes da capital maranhense, ocupando o cargo de Primeiro Secretário da ACM, se gradua como bacharel em Ciências Jurídicas e Sociais pela Faculdade de Direito do Maranhão, com inscrição na Ordem dos Advogados do Brasil, seccional local, de número 111. Não advogou, porém, dedicando-se quase exclusivamente à atividade empresarial. Igual a si é Arnaldo de Jesus Ferreira, também bacharel em Direito e Contador, que será presidente da Associação Comercial do Maranhão nos anos 1950.

Por seu turno, Temístocles Aranha, em 1853, ingressou no curso de engenharia, na Corte Imperial do Rio de Janeiro, precisamente na "Escola Central", onde foi colega de classe de André Rebouças (1838-1898), futuramente um dos principais engenheiros do país, desenvolvendo inclusive um projeto de desobstrução do porto de São Luís. Contudo, quatro anos depois, Temístocles não defendeu os trabalhos finais, do mesmo modo voltando para a capital maranhense, e por razões semelhantes às de Arnaldo Júlio. Temístocles, além de escritor, fora promotor de justiça, procurador seccional no Rio de Janeiro e diplomata.

A esposa de Temístocles, Maria da Glória da Graça, provinha de uma linhagem com grande inserção no Direito. Era mãe do escritor maranhense José Pereira da Graça Aranha, 
inicialmente membro da Academia Brasileira de Letras e filha do cearense José Pereira da Graça Júnior (1812-1889), que recebeu o título de Barão de Aracaty no ano de 1887 em razão dos serviços prestados à administração da justiça. Esse foi bacharel em direito pela Academia de Ciências Jurídicas e Sociais de Olinda e deputado pelo Ceará durante várias legislaturas, além de compor a Assembleia Geral do Império por dois mandatos. Muda-se para o Maranhão com mulher e filhos na década de 1860, quando se tornou presidente de província, função que ocupou por quatros vezes consecutivas. Em 1876 fixou-se no Rio de Janeiro, nomeado por Pedro II como desembargador do Tribunal da Relação (órgão máximo do Poder Judiciário da época, cujo equivalente hodierno é o Supremo Tribunal Federal).

Caso paradigmático é o bloqueio sofrido por João Dunshee de Abranches Moura (1867-1941) na Associação Comercial do Maranhão, e que o conduz a outros investimentos. Apesar de sua família ser muito próxima de Temístocles Aranha, editor do jornal "O País”, que estava sempre a publicar os eventos realizados pelo colégio pertencente à sua mãe (MOURA, 1992, p. 98), não conseguiu, nessa entidade, o reconhecimento que almejava. Mas o capital de relações constituído por seus antecedentes, além do processo de socialização por ele experimentado, permitiu a Dunshee de Abranches formar um círculo de amizades com outros jovens pertencentes às elites políticas, econômicas e intelectuais locais (MOURA, 1992, p. 132147):

Carlos Moreira da Silva, filho do Visconde Itaqui, Domingos Coco Ribeiro e Francisco Nina, que eram inseparáveis, quiseram juntar-se ao nosso grupo, entrando na luta pela redenção dos cativos [...]. Resolvemos então, com o auxílio de alguns colegas endinheirados, como Domingos Coco Ribeiro, Álvaro Sá e Carlos Moreira da Silva, alugar uma meia morada à Rua dos Afogados em face da Travessa do Teatro, para ali reunir livremente o Diretório dos Cinco, como passamos a designar-nos e acoutar os escravos que quisessem fugir para o Ceará.

Nesse tempo, Dunshee de Abranches contava quinze anos pouco mais ou menos. No entanto, essa não era, propriamente, uma idade precoce para se principiar o manejo de temas políticos. A produção e o recrutamento de lideranças nessa esfera se dão logo após a infância ou durante a puberdade. Os chamados “caixeiros", por exemplo, aprendizes do comércio, eram engajados na vida cotidiana do estabelecimento a partir dos oito ou dez anos. Entre os quinze e dezoito, já deveriam estar relativamente aptos a assumir os postos de comando. Isso terminava por contribuir, com grande força, para que posteriormente o agente e os indivíduos que em seu

Rev. de Sociologia, Antropologia E Cultura Jurídica | e-ISSN: 2526-0251 | Goiânia| v. 5 | n. 1 | p. 1-22| Jan/Jun. 2019 
entorno conviviam, acreditassem em uma "vocação" natural para aquela "profissão", ainda que depois procurassem formação superior em outras áreas, como o Direito. Observou Canêdo (1991, p. 233):

\begin{abstract}
Cumprimentar convidados, parentes e amigos, aprender a sorrir, deixar brinquedos e freqüentar festas de casamento [...], escutar distraidamente conversações de políticos, acompanhar o trabalho os eleitores e a "elevação da temperatura" na vida familiar às vésperas das eleições, perceber os pequenos cuidados necessários para dominar os detalhes do jogo básico do homem político, tudo isso faz parte da conduta regular de uma criança e representa a forma a forma de capital mais importante dentre todas as que constituem investimento para o sucesso na carreira política.
\end{abstract}

Assim, no caso de Dunshee de Abranches, a subsidiar grandemente seu ingresso na arena política, havia o "legado" deixado pelo avô, militante político no Primeiro Reinado, o convívio dentro do lar com profissionais liberais contrários ao regime de trabalho servil e à Monarquia, além do incentivo dos pais na aproximação do filho com esses últimos, sob o credo de que isso fortaleceria sua "educação". Já aos dezessete anos, enquanto se dirigia para o Rio de Janeiro a fim de ingressar em um curso superior, durante uma escala na cidade de Fortaleza, conheceu o abolicionista José Correia do Amaral, tido como um dos responsáveis pelo fim da escravidão no Ceará. Na oportunidade, “[...] ao receber-me com a hospitalidade inata dos nortistas, fixou a vista sobre o cartão, com o que me anunciara, e encarou-me um tanto surpreendido... - Acha-me muito criança? Indaguei. - Não senhor; aqui pelo Ceará, há muitos mocinhos abolicionistas também [...]” (MOURA, 1992, p. 164).

Uma vez na Corte, hospedou-se em uma república onde reconheceu um ator que havia estado em São Luís, e que lá mantivera um caso amoroso com uma dama, cujo marido, rico empresário, estava em viagem de negócios a Portugal. O ocorrido havia sido comentado em sua residência, e ele conhecia os detalhes da trama. As relações amistosas com o ele, Eugênio de Magalhães, proporcionaram a Dunshee de Abranches o acesso aos teatros da cidade, além de ser apresentado a pessoas de influência na capital do Império, muitos ligados às profissões do Direito (MOURA, 1992, p. 175):

Foi assim que Lucinda Simões me aproximou de Sizenando Nabuco; e este me fez conhecido não só do seu glorioso irmão, o grande Joaquim Nabuco, como de Patrocínio, João Clapp, Campos da Paz e outros ardorosos agitadores da época. Rev. de Sociologia, Antropologia E Cultura Jurídica | e-ISSN: 2526-0251 | Goiânia| v. 5 | n. 1 | p. 1-22| Jan/Jun. 2019 
Também nessas rodas que, depois das dez horas noite, se viam nos jardins das casas de espetáculos, duas figuras que bastante me interessaram: o Conselheiro Silveira da Mota e Paula Ney, cujo espírito revolucionário de nortista muito se assemelhava ao meu. Naquele emérito parlamentar e homem de letras, pai do Barão de Jaceguay [...] achei um admirável mestre da história política de nossa Pátria.

Após a queda da Monarquia, os que se ajustaram à nova forma de governo foram de grande valia para o recebimento de Dunshee de Abranches nas mais elevadas instâncias de poder na Capital Federal durante seu mandato de deputado no Governo Provisório de Deodoro da Fonseca. No mais, retornara ao Maranhão ainda no Império. Após a conclusão do curso de jurídico, participa ativamente do processo de emancipação do trabalho escravo, fazendo comícios e promovendo encontros de abolicionistas e republicanos em torno de um grupo por ele fundado sob o título de "Centro Artístico Abolicionista Maranhense".

Quando noticiada a assinatura da Lei Áurea, toma parte em uma reunião na Câmara Municipal de São Luís, onde estavam presentes os principais líderes políticos da Província. "No dia seguinte, após a oferta da pena de ouro, feita por mim em Palácio, como orador oficial do Centro Artístico Abolicionista Maranhense, ao presidente da Província, a fim de assinar os comunicados da decretação da lei redentora aos municípios do interior, realizava-se no Teatro São Luís o festival acadêmico." (MOURA, 1992, p. 196). Nessa ocasião, Dunshee de Abranches havia proferido um discurso em favor dos cativos e, sob essa alegação, foi convidado pelo presidente da Província, José Moreira Alves da Silva, a participar de um almoço de agradecimento no Palácio do Governo. Entrando no local (MOURA, 1992, p. 197):

[...] uma jovem de vinte anos aproximara-se de mim, abraçando-me e conduzindo-me à presença do presidente da Província: 'Aqui tem, Dr. Moreira Alves, disse-lhe sorrindo alegremente, um dos heróis do dia; já era abolicionista e revolucionário aos onze anos de idade [...]'. Era a filha mais moça do comendador Casusa Lopes, a minha boa companheira de infância, naquela hora, noiva do Comandante Barros Barreto, parente próximo do presidente.

Dunshee de Abranches tinha em Moreira Alves um aliado político, através da influência de Carlos Fernando Ribeiro, o Barão de Grajaú, que contribuíra diretamente para a sua nomeação como promotor de justiça, justamente em um de seus redutos eleitorais mais fortes, a vila de Grajaú, no sertão maranhense. Mas ainda pouco antes disso, com o colapso do 
sistema escravista, a perda patrimonial de muitos lavradores teria se agravado com a célere extração de braços para os seringais da Amazônia, cuja economia estava em franca expansão. Assim, o governo da Província, através de Moreira Alves, convocou uma audiência com os principais empresários locais, incluindo-se comerciantes, industriais, agricultores e banqueiros para deliberarem sobre as soluções possíveis de adoção naquele cenário. De pronto a ACM se engajou nos debates e abriu um concurso monográfico com prêmio em dinheiro para quem melhor desenvolvesse uma estratégia prática de transformação do trabalho compulsório ao remunerado.

Dunshee de Abranches informa que redigira a sua memória, de mais de sessenta páginas, em "menos de uma semana" (MOURA, 1993, p. 34), isso como uma prova indelével de seu conhecimento técnico, adequado ao que a instituição demandava. Quando pronta, fizera a leitura da mesma em uma "reunião íntima" com vários diretores da Associação Comercial, dentre eles Theodoro José de Abreu Sobrinho, Cirino Ribeiro, Anacleto Tavares, Ramiro Costa e Cândido César da Silva Rios, este vereador de São Luís. A opinião geral foi que o texto em questão, intitulado "Transformação do Trabalho: memória apresentada à Associação Comercial do Maranhão" seria o vencedor. Contudo, a sua articulação tinha a concorrência de outra talvez mais forte, tocada pelo consultor jurídico e secretário da própria ACM, a quem Dunshee de Abranches se refere em flagrante desprezo e com o objetivo de desqualificá-lo, sob a identificação de "[...] Dr. Faboca, apelido familiar com que era conhecido ilustre advogado [...]", e que se dizia já ser antecipadamente o ganhador do prêmio (MOURA, 1993, p. 35). No dia da abertura da sessão de premiação, Dunshee de Abranches discursa enfatizando os trunfos que dispunha para colocar em jogo naquele momento, ou seja, os laços de parentesco e os vínculos de reciprocidade (MOURA, 1993, p. 36):

Ao contrário do que se murmurava, fui logo declarando que os representantes, ali presentes, do alto comércio maranhense, decerto não estranhariam a intervenção neste magno debate de um moço de vinte anos. Poderia talvez dizer sem errar que algumas figuras respeitáveis que via em minha frente haviam passado pelo balcão da casa comercial de meu pai. E que este fora seu patrão e seu mestre, não somente me instruíra em escrituração mercantil como me despertara o gosto pelos estudos de Economia Política e Finanças. Descendia também de uma família de lavradores e industriais, e tinha orgulho de recordar ali que, há setenta anos passados, já o meu avô, Garcia de Abranches, o Censor, chamava a atenção dos governos e governados do 
Brasil para o gravíssimo erro de se querer colonizar o País com os negros da Costa da África, reduzidos à mísera condição de escravos.

Como que o consultor jurídico da Associação Comercial se manifestasse apresentando sua obra, informando também que recebera outras ainda naquele dia, e que por esse motivo seriam incluídas na análise da comissão de empresários, a divulgação do nome do ganhador se daria pela imprensa. Dunshee de Abranches relata que, pelos aplausos e congratulações que recebera, aguardava ser o vitorioso: “[...] o prêmio anunciado não poderia deixar de me ser conferido." (MOURA, 1993, p. 38). Entretanto, a "memória" vencedora foi outra. A ACM divulgara que Dunshee de Abranches não poderia receber a premiação, apesar da qualidade de seu texto, porque ele havia fugido aos fins previstos do certame. O escritor atribuiu a responsabilidade de sua derrota não ao debate técnico, mas à “[...] má vontade dos escravocratas de São Luís contra um de seus adversários na campanha abolicionista [...]” (MOURA, 1993, p. 35), que serrariam também as fileiras da entidade.

Assim mesmo, a sua "Transformação do Trabalho" foi editada pela Tipographia da Pacotilha em 1888 por dois amigos empresários, “[...] em sinal de desagravo da parte sã e culta do comércio maranhense" (MOURA, 1993, p. 39). Apesar do bloqueio inicial por parte da ACM, nem por isso Dunshee de Abranches deixou de falar pelo empresariado quando ocupou cadeira no parlamento federal, isso conforme os interesses dos agentes com os quais mantinha vínculos de reciprocidade.

Apesar dos formados em Direito que transitam pela Associação Comercial do Maranhão, verificou-se que existe de fato uma predominância de cursos da área de contabilidade, provavelmente em virtude da aplicabilidade imediata no exercício comercial quando os agentes ainda não gozavam da consagração profissional. $\mathrm{Na}$ ordem numérica, são 8 contadores, 3 bacharéis, 2 técnicos comerciais ou industriais, 2 militares e 1 farmacêutico. A obtenção de diferentes tipos de formações acadêmicas, em especial as de notório reconhecimento, redunda também na dedicação, ainda que meramente acessória, a atividades não propriamente empresariais, como a de professor em cursos do "Centro Caixeiral" (formador de contadores), faculdades, seminários e mesmo no ensino secundário, é tributária da formação de uma personalidade de múltiplas relações e conhecimento, apropriada à liderança.

Apesar da ocupação dos cargos na Associação Comercial por militares não poder ser associada diretamente à conjuntura política republicana de nível nacional - o primeiro, 
Francisco Xavier de Carvalho, foi diretor em 1881, e o segundo, Manoel Ignácio Dias Vieira, entre 1897 e 1901, já durante o governo civil do presidente Prudente de Morais (1841-1902) os membros das forças armadas passaram a usufruir de crescente prestígio político após a campanha brasileira na Guerra do Paraguai. Interessante é se notar que as suas origens sociais e trajetórias profissionais não são similares àquelas apresentadas como as ordinárias para os empresários do comércio. Não são imigrantes. Provinham de abastadas famílias e grupos associados ao mundo rural escravocrata. Francisco Xavier de Carvalho exerceu apenas um mandato de segundo-secretário da Associação Comercial, durante a Monarquia.

Contudo, portando nos pulsos galões de Tenente-Coronel, foi indicado para compor a Junta Provisória instalada em 18 de novembro de 1889, que tomou posse do governo da Província agora transformada em Estado do Maranhão. O responsável pela indicação foi José Francisco de Viveiros, um dos líderes do Partido Conservador maranhense, proprietário do engenho Tramaúba, na Baixada Maranhense, e filho do Barão de São Bento.

José Francisco de Viveiros graduou-se na universidade de Direito de Recife, em 1862, advogado e deputado provincial por várias legislaturas, e uma na Assembleia Geral, na Corte. Ele próprio foi um dos componentes da primeira junta provisória republicana, passando em seguida para o cargo de conselheiro da Intendência (antiga nomenclatura da Prefeitura) de São Luís, ao lado do poeta Joaquim de Sousa Andrade, o "Sousândrade". Seu pai tinha por graça o nome de Francisco Mariano de Viveiros Sobrinho. Nasceu e morreu na mesma cidade de Alcântara, a 12/01/1819 e 10/01/1860. Era filho de um dos mais ricos lavradores maranhenses do início do século dezenove, Jerônimo José de Viveiros, senador do Império. O Barão de São Bento estudou Direito em Coimbra, graduando-se em 1839 (COUTINHO, 2005, p. 314).

Como muitos outros descendentes da aristocracia rural brasileira, retornou de seus estudos não para exercer a profissão na qual se titulou, mas para administrar os negócios da família. É no esteio de linhagens como essa que Francisco Xavier de Carvalho, e outros, encontram o apoio necessário para suas carreiras políticas. Sobre esse tipo de relação caracterizada pela vinculação familiar, em situações de não parentesco, é tanto mais lucrativa quanto os regulamentos oficiais são frágeis ou a busca por sua eficácia gere dispêndios elevados (WOLF, 2003, P. 102):

A vantagem mais óbvia desse tipo de relação apareceria, portanto, em situações em que a lei pública não pudesse garantir proteção adequada contra rupturas de contratos Rev. de Sociologia, Antropologia E Cultura Jurídica | e-ISSN: 2526-0251 | Goiânia | v. 5 | n. 1 | p. 1-22| Jan/Jun. 2019 
com não-parentes. Isso pode ocorrer quando a lei pública é fraca ou onde não existem padrões culturais de cooperação entre não-parentes que orientam a relação requerida.

$[\ldots]$

Finalmente, cooperar é útil aos parentes onde o acesso à lei acarrete custos e complicações de tal ordem que deixariam os parceiros em disputa deprivados economicamente ou de qualquer outra forma, após a resolução da disputa.

Outro egresso da ordem rural escravocrata que alcançou a presidência da Associação Comercial do Maranhão por cinco mandatos consecutivos e sem ocupar qualquer outra posição anterior a essa, dentro de tal instituição, é Manoel Ignácio Dias Vieira, entre os anos de 1897 e 1901. É pertinente se evidenciar que Tenente-Coronel Francisco Xavier e o Coronel Manoel Ignácio não comungavam apenas das mesmas fileiras do braço armado. Outro membro da família Dias Vieira, Casimiro Dias Vieira Júnior (1853-1897), ou simplesmente "Casimiro Júnior", como ficou conhecido, e que depois emprestaria seu nome à principal avenida do atual bairro do Anil na cidade de São Luís, era promotor público, deputado provincial e constituinte, e foi nomeado Chefe de Polícia da junta governativa republicana, ou seja, laborou ao lado do Coronel Francisco Xavier de Carvalho.

A chefatura de polícia não era um cargo menor a esse tempo. Ao contrário, ao delegado chefe estava destinada uma importante missão: perseguir os defensores do regime monárquico decaído e, sob essa justificativa, anular rápida e objetivamente toda e qualquer oposição ao novo governo e seus representantes (LIMA, 2010, p. 34): "Casimiro Júnior, Chefe de Polícia, promoveu verdadeira caçada aos 'inimigos do regime', submetendo-os a pranchadas e palmatoadas, mandando raspar-lhes as cabeças.”. Um parente muito próximo the havia nomeado para a função: o primo e então governador, militar da Armada, Manoel Ignácio Belfort Vieira (1854-1913).

Todos esses, incluindo o Coronel Manoel Ignácio Dias Vieira, que tomou posse do cargo no mesmo ano do falecimento do Delegado Casimiro Júnior, eram descendentes de uma das mais antigas famílias maranhenses, que se instalou no entorno da Baía de Cumã, posterior à cidade de Alcântara, no litoral Oeste do antigo Estado, na segunda metade do século dezoito. A fundação da vila de Guimarães, o principal centro político-econômico da vasta área que partia da desembocadura do Rio Pericumã até o Pará, está relacionada à ocupação feita por dois de seus ancestrais diretos, o capitão Manoel Ignácio Vieira e Manoel Dias Cadete. 
O Coronel Manoel Ignácio Dias Vieira nasceu na ampla morada térrea da família, localizada dentro da vila, em 1858. Herdou do pai o nome, absolutamente idêntico. Porém, o superou quanto à patente militar alcançada, pois seu ancestral havia sido tão somente TenenteCoronel. Faleceu o progenitor quando o pequeno Dias Vieira tinha apenas dois anos (FURTADO FILHO, 2000, p. 79). Sua mãe, Anna Cantanhede, era proprietária do "Engenho Coberta", também em Guimarães, e contraiu núpcias com o seu cunhado, Casimiro Dias Vieira, tendo ambos se retirado para viverem na "Fazenda Santa Maria", de propriedade deste último, onde o futuro diretor da ACM conviveria com novo casal até os doze anos.

Os Dias Vieira, de longo tempo, sempre estiveram muito próximos da administração política portuguesa, imperial e republicana no Maranhão. Para isso contribuiu uma "forte tradição militar", emanada das carreiras comuns de vários de seus membros dentro do oficialato das forças armadas, do final dos setecentos, até o início do século vinte. É relevante o fato de alcançarem sempre postos de comando superior em suas organizações (em ordem cronológica): Capitães Manoel Ignácio Vieira e Manoel Dias Cadete; Coronel Manoel Ignácio Dias Vieira; Tenente-Coronel Joaquim Cantanhede Dias Vieira; Major Casimiro Dias Vieira; Coronel Pedro Wenescop Dias Vieira; Almirantes Ricardo Salazar Dias Vieira e Manoel Ignácio Belfort Vieira, além do Capitão Gastão Cantanhede Dias Vieira.

Manoel Ignácio Dias Vieira não se ocupava apenas da presidência da Associação Comercial do Maranhão no alvorecer dos novecentos. Preparava sua eleição para o mandato de deputado federal, na legislatura que se iniciaria em 1903. Para tanto, necessitou deixar a entidade para assumir o posto de Segundo Vice-Governador, na administração de outro político nascido em nas mesmas plagas que ele, Urbano Santos da Costa Araújo, que seria vicepresidente da República durante o governo de Venceslau Brás (1914-1918).

Urbano Santos formou-se pela Faculdade de Direito do Recife em 1882 na mesma turma de Clóvis Beviláqua. Ocupou o cargo de promotor público nas cidades de Vitória do Mearim, Mirador e Rosário, depois assumindo a magistratura nas cidades de Coroatá, São Bento e São Vicente Ferrer. Por mim, foi juiz de casamentos e do comércio na capital.

Dias Vieira, a partir da posição alcançada, e contando com o apoio ostensivo de seu conterrâneo, consegui formar as bases de uma vitória certa. Ao final de 1902 já embarcava para o Rio de Janeiro. Com o término de seu primeiro mandato na Câmara Federal, tentou reeleger- 
se, mas não conseguiu. Retornando ao Maranhão, concorreu à vereança de São Luís, obtendo uma cadeira no parlamento municipal, do qual foi também presidente. Seus trabalhos como empresário não foram de grande projeção. O único empreendimento de vulto do qual participou foi a "Companhia de Fiação e Tecidos São Luís", proprietária da fábrica homônima, localizada no bairro da Madre-Deus. Sob sua administração, a sociedade anônima concluiu a edificação da têxtil, mas não conseguiu colocá-la em funcionamento, restando mesmo material importado retido na alfândega por falta de pagamento das taxas de liberação:

Companhia de Fiação e Tecelagem São Luiz

- Venda da Fabrica -

A commissão abaixo assignada recebe proposta em carta fechada para a venda da fabrica de fiação e tecidos de algodão de propriedade da Companhia, sita à rua de $\mathrm{S}$. Pantaleão desta cidade. Esta fabrica construída na quinta BOA HORA, local salubre, terrenos de grandes dimensões e abundante d'agua dispondo de 6 poços, offerece fácil transporte por terra e por mar, recommendando-se pelo seu material todo novo e bem conservado e está apercebida de 55 teares e machinismo de fiação para trabalhar com mais 30 teares produsindo mensalmente de 26 a 28.000 metros de tecidos de diversas larguras, podendo trabalhar em acto continuo a venda, visto ter grande quantidade de fio em diversos grãos de laboração em todo machinismo.

N'Alfandega ainda se achão alguns aparelhos de fiação e teares sujeitos a despacho que também fazem parte da fabrica.

Os immoveis, machinismo e fio estão a Companhia pelo valor de rs. 474:000\$000.

As propostas serão apresentadas até o dia 30 de julho vindouro e ficarão dependendo de approvação da Assembléa Geral dos accionistas que será previamente convocada.

Maranhão, 23 de Abril de 1897.

Manoel Ignácio Dias Vieira. [GRIFO NOSSO]

Acrisio Tavares.

Salustiano Faria.

(A Pacotilha. 24/05/1897)

Exerceu ainda a tesouraria da "Companhia Usina Castelo", beneficiadora de arroz de porte mediano, localizada na periferia de São Luís, e foi sócio-proprietário de outro empreendimento sediado em Guimarães, a “Usina João Antônio”. Encerrou sua carreira política integrando a sétima legislatura do Congresso Estadual, entre 1910 e 1912, vindo a falecer três 
anos depois. Como é possível perceber, seu ingresso e permanência no cargo mais elevado da Associação Comercial do Maranhão não se deu a partir da carreira de empresário. Os feitos pessoais nesse sentido são absolutamente limitados. Chega mesmo a ser difícil classificá-lo nas categorias de "comerciante" ou "industrial", e nem as fontes pesquisadas o fazem.

Um dos empresários e diretor da Associação Comercial do Maranhão de maior destaque na política estadual nas décadas de 1930-1950 foi Alarico Nunes Saturnino Bello, interventor federal, vice-governador e governador eleito, mas não empossado, no início dos anos cinquenta. Sua família é originária de São Luís e possuía laços de parentesco com os Parga, ou Bello Parga, que por sua vez tivera um de seus membros como governador do Estado, o advogado Herculano Parga, entre 1914-1918.

Consta que ele, apesar de sua "absoluta honestidade" (LIMA, 2010, p. 91), não esqueceu sua ascendência, concedendo benefícios ao empreendimento econômico de seu pai, Ignácio do Lago Parga, duas vezes primeiro-secretário da ACM: “[...] a proteção que o governador Herculano dá a seu pai Inácio do Lago Parga, principal acionista e gerente da Companhia de Águas, cujos serviços, além de deficientes e incertos, fornecem líquido de péssima qualidade [...]” (LIMA, 2010, p. 94).

A família de Saturnino Bello era proprietária do mais antigo cartório de São Luís, instituído na primeira década do século dezenove, ainda durante a regência de D. João VI. Seus avós e pais investiram também no comércio de importação de artigos, e com o capital financeiro legado a Saturnino Bello, foi possível a ele participar da fundação da maior indústria têxtil do Estado, a Companhia Fabril Maranhense, já no final do Oitocentos.

Frente a tais circunstâncias, é impossível se ocultar a constatação de que os mecanismos de reprodução das estruturas de poder lastreadas essencialmente nas relações diretas de parentesco, e outras derivadas dessa mesma lógica, utilizando em algum momento das trajetórias pessoais o capital acadêmico, não somente contribuem para a hierarquização das posições de comando na Associação Comercial do Maranhão, como também são as bases primordiais de sua própria existência.

\section{Conclusão}


Os estudos sobre a formação das elites "intelectuais", "políticas" ou "econômicas" do final do século dezenove e início do vinte indicam a existência de condicionantes locais de organização, sempre a partir dos vínculos de comprometimento interpessoal e utilização do saber técnico (jurídico, econômico, institucional, etc.) acumulando recursos socialmente válidos para a escolha dos agentes que se tornarão líderes, durante as disputas pela legitimação e permanência nos lugares de poder.

Através da Associação Comercial do Maranhão, enquanto instância de consagração acessada através de múltiplos instrumentos legados ou alcançados pelos agentes, se pode perceber que o Direito - ou pelo menos a titulação formal nessa disciplina -, não é, sozinho, um caracterizador ou definidor do líder, ou ainda de uma tipologia genérica em um determinado contexto histórico. Com efeito, pode ser recurso importante, mas apenas em meio a vários outros, e nem mesmo o determinante. O portador do diploma, nesse caso, não é um "especialista", pois as trajetórias demonstram múltiplos investimentos ao longo da vida, ao ponto de impossibilitar qualquer tentativa de classificação pessoal ou de grupo nesse sentido.

Assim, no Entresséculos maranhense, o "empresário" não existe enquanto tal, e nem mesmo o "bacharel". Por consequência, também nenhuma extensão coletiva que parta desses conceitos. Apesar de haver similitudes entre os perfis que tornam possível a identificação de uma "elite", as mutações decorrentes da permanente concorrência entre os agentes, nesse tipo de organização social, impedem a formação de uma visão uniforme e colegiada do mundo.

As relações construídas em um ambiente de inexistência de especializações, fluidez institucional e alto acúmulo de recursos com força simbólica entre os pares, indica que as formas de diferenciação, dentre elas a formação acadêmica, devem estar disponíveis conjugadamente aos laços de parentesco e à estruturação de vínculos a eles equivalentes, como a reciprocidade e o compadrio, sempre acionados. Em conjunto, eles serão definidores de quem é apto a constituir os quadros dirigentes, seja nas entidades privadas, seja nos organismos da Administração Pública.

\section{Referências}

ALONSO, Angela. Ideias em movimento: a geração 1870 na crise do Brasil-Império. São Paulo: Paz e Terra, 2002. 
ANDRADE, Oswald de. Manifesto da Poesia Pau-Brasil. São Paulo: Revista de Antropofagia, ano $1, \quad \mathrm{n}^{\mathrm{o}} 1, \quad 1928 . \quad$ Disponível em: http://www.letras.ufmg.br/padrao_cms/documentos/profs/sergioalcides/OswaldManifestos.pd $\underline{\mathrm{f}}$

BOURDIEU, Pierre. O poder Simbólico. Rio de Janeiro, Bertrand Brasil, 2007.

CANÊDO, Letícia Bicalho. Estratégias familiares na produção social de uma qualificação política. Campinas: Unicamp, 1991.

COMPANHIA de Fiação e Tecelagem São Luiz. A Pacotilha, São Luís, 25 mai. 1897. p. 3.

CORADINI, Odaci Luiz. Panteões, iconoclastas e as ciências sociais. In: FÉLIX, L. O. e ELMIR C. P. (orgs) Mitos e heróis: construção de imaginários. Porto Alegre: Editora da UFRGS, 1998.

COUTINHO, Milson de Sousa. Fidalgos e Barões, uma história da nobiliarquia lusomaranhense. São Luís: Geia. 2005.

FREYRE, Gilberto. Casa Grande \& Senzala. Rio de Janeiro: Nova Aguilar, 2002.

FURTADO FILHO, Douglas. História dos Dias Vieira (livro de família). São Luís: 2000.

HOLANDA, Sérgio Buarque de. Raízes do Brasil. São Paulo: Companhia das Letras, 1995.

LANDÉ, Carl H. A Base Diádica do Clientelismo. In: Political Clientelism in Political Studies. 1977.

LIMA, Carlos de. Caminhos de São Luís: ruas, logradouros e prédios históricos. São Paulo: Ed. Siciliano, 2002.

LIMA, Carlos de. História do Maranhão. São Luís: Geia, 2010.

MILLS, Charles Whight. The Power Elite. New York: Harper, 1957.

MOURA, Dunshee de Abranches. O Cativeiro. São Luís: ALUMAR, 1992.

MOURA, Dunshee de Abranches. A Esfinge do Grajaú. São Luís: ALUMAR, 1993.

OFFERLÉ, Michel. Sociologie des Organisations Patronales. Paris: La Découverte, 2009.

REIS, Eliana Tavares. Saberes em movimento: transações entre "intelectuais", definições de ciências sociais e política. In: SEIDL, Ernesto; GRILL, Igor Gastal. (Orgs.). As ciências sociais 
e os espaços da política no Brasil. Rio de Janeiro: FGV, 2013, p. 21-74.

REVISTA DA ASSOCIAÇÃO COMERCIAL DO MARANHÃO. São Luís, ACM, 19251954.

WOLF, Eric. Antropologia e poder. Organizado por Bela Feldman-Bianco e Gustavo Lins Ribeiro; tradução de Pedro Maia Soares - Brasília: Editora da Universidade de Brasília: São Paulo: Imprensa Oficial do Estado de São Paulo: Editora Unicamp, 2003. 